\title{
Global launch event of the International Year of Planet Earth
}

\author{
UNESCO. Paris, 12-13 February 2008
}

The Global Launch Event of the International Year of Planet Earth (IYPE), proclaimed by the United Nations' General Assembly for 2008, took place on 12 and 13 February 2008 at the Paris headquarters of UNESCO.

The aim of this Event, involving input from all 68 IYPE national committees, was to put across the message of the International Year to decision makers and the public at large. We should all be making better use of the knowledge and outcomes of Earth science when framing planning and management decisions. Equally, we should all be using the skills and products of Earth science to influence the sustainable use of Earth resources, to make the world a healthier, wealthier and safer place for all.

Following the introduction of the events of the two-day celebration by the Master of ceremonies, Ted Nield (Geological Society of London and Chair of the IYPE Outreach Programme), Koïchiro Matsuura, Director-General of UNESCO addressed the audience of almost one thousand participants. Mr. Matsuura spoke of the fundamental role of the Earth sciences in securing a healthy Earth system that is vital to informed planning of sustainable development in the face of challenges-including climatic change.

He laid great emphasis on the serious implications of the fact that, in rich and poor countries alike, the numbers of students studying science are declining. This threat to the survival of university geology departments, if not reversed, will effectively cut off from society the Earth scientists of the future in a world in which the demand for sources of energy and raw materials will be with us for many decades to come as world population approaches nine billion.

In welcoming politicians, prominent members of geosciences institutions and leaders from within the business sector, he stressed the importance of the societal dependence on the Earth sciences on a day to day basis, so that while the Global Launch Event marks a peak achievement by the world's geoscientists, it constitutes only a starting point in improving understanding of the richness and diversity of Earth science by the global community.

Zhang Hongren (P. R. China), as President of the International Union of Geological Sciences (IUGS) and co-initiating organization of the International Year with UNESCO, spoke of the need for both leaders and public to make optimal use of the Earth sciences in protecting the Earth system. This is best done by adopting wise practices and protecting the Earth's inhabitants by using science to min-

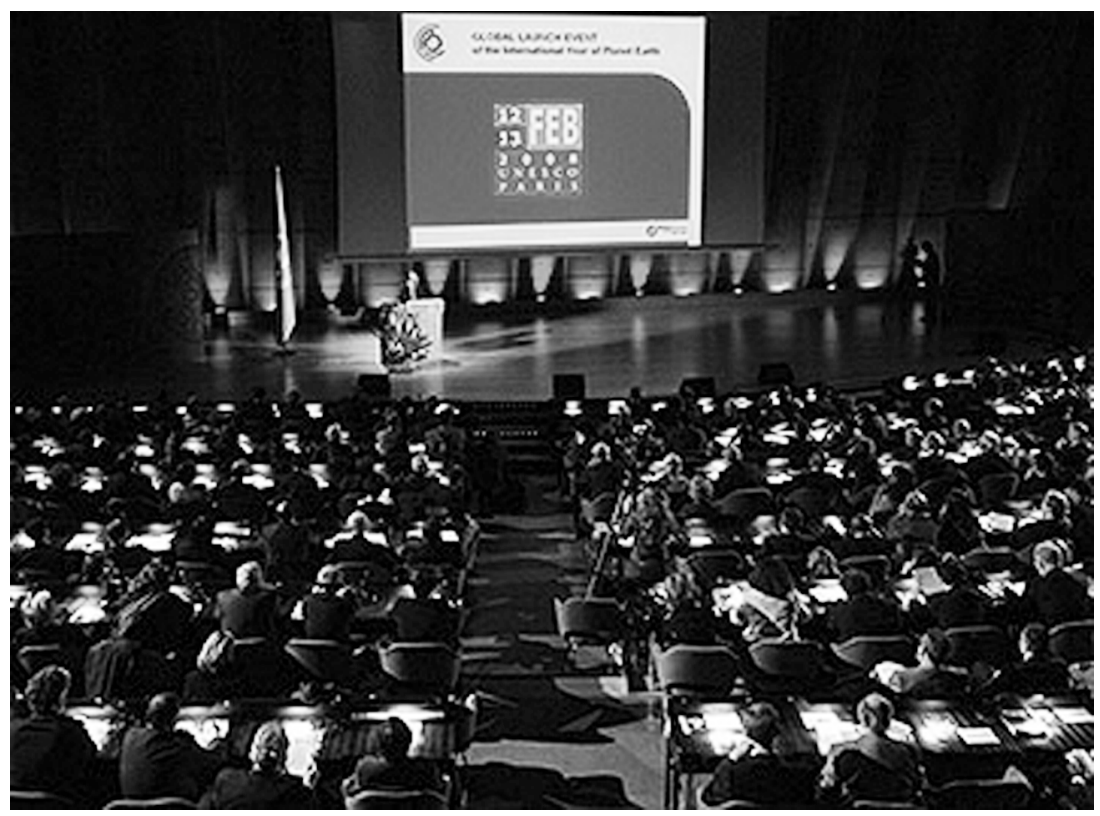

Opening of the International Year of Planet Earth at UNESCO Headquarters, Paris, 12 February 2008.

imise the impact of both natural and humaninduced risks.

The sustained efforts of the many scientists shouldering the burden of work for seven years to realize the IYPE in general and this event in particular were paid tribute to by Larry Woodfork, Chair of the International Year of Planet Earth Corporation. He emphasised the importance of the 10 geoscientific themes of the IYPE-Earth and Life; Climate; Health; Resources; Megacities; Geohazards; Groundwater; Soil; Deep Earth; and Ocean-and the potential of outreach activities that should extend well beyond the formal closure of the IYPE triennium in December 2009.

Jean-Pierre Jouyet, Minister of State in the French Ministry of Foreign and European Affairs, spoke to the effect that the twin facts of a changing climate and a burgeoning world population must be a priority for the French Presidency of the European Union in the second half of 2008. He noted the significant contribution already made to the IYPE by French geoscientists and wished the venture, which also marks the opening of the IYPE in France, every success.

There followed a number of short statements by government ministers and United Nations representatives. A clear awareness of the character of the IYPE and the need for outreach initiatives of this kind was evident in the statement by Tora Aasland, Minister of Research and Higher Education, Norway, who announced full commitment to, and considerable financial support for the activities of the IYPE in Norway, including support for the International Secretariat. In his five statements Hany Helal, Minister for Higher Education and Scienfitic Research of Egypt, endorsed this conceptual view. He shared with the audience Egypt's ambitions to arrive at $20 \%$ renewable energy in 2020 and a very significant ambition in energy savings.

The representative of the Minister for Higher Education, Science and Technology of the United Republic of Tanzania described the process of UN proclamation in which Tanzania played an initiating and decisive role. Also, the need of more geoscientific input in decision making in Africa was stressed and an invitation to participate in the African Launch Event to be held in Arusha, Tanzania, in May 2008 was extended to all. A statement on behalf of the Italian Minister of Environment, Land and Sea emphasized the full commitment and significant financial support provided by the Italian government. The representative went on to encourage nations to work on the IYPE legacy by stressing the need for realization of an international Research Centre on Earth sciences for sustainable development. A more wideranging discourse was presented by Arab Hoballah, Chief of the Sustainable Consumption and Production Branch of the Division of Technology, Industry and Economics of UNEP. 
The scene then shifted from tributes, statements, explanations and ambitions to the ultimate example of a formal group letter of intent, called the Paris Declaration. The specific aims and objectives of the IYPE include urging decision makers the world over to make knowledge of Planet Earth freely available, to encourage development of new knowledge for the benefit of all nations, and to encourage support of the initiatives from all quarters of society so as to reduce natural hazard impact and guide sustainable development for generations to come (see page 270).

These aims are to be achieved by reviving and enhancing national educational systems and research capacity in Earth and space science institutions and universities; by producing global, digital and publicly available information on System Earth via projects such as "OneGeology" and "UN Spatial Data Infrastructure" (UNSDI); by promoting awareness of the structure, evolution, beauty and diversity of the Earth system and its human cultures inscribed in landscapes, through the establishment of "geoparks", biosphere reserves and World Heritage Sites as a public tool for conservation and development; by investing in Earth monitoring mechanisms as means of predicting large-scale changes in the Earth's spheres, using and enhancing existing global Earth observation systems; by producing books, DVDs and other media tools that will make Earth scientific knowledge much more accessible and provide a lasting legacy of the IYPE; and finally, by establishing an International Research Centre on Earth sciences for sustainable development.

After the UNESCO Director-General spoke about the IYPE's ambitious targets, Aubrey Manning (Emeritus Professor, renowned zoologist and television and radio broadcaster) enlivened the proceedings with a vision of the essentials of the Earth system.

The afternoon session began with the performance of a 'geo-song' called Mother Earth. This specially-composed item was sung with instrumental accompaniment by some 100 students who hailed from all continents of the world and were present as guests of the IYPE; they were selected from among the many students who participated in a world-wide Geo-Contest. The effort made by the members of the student choir, who had come together for the first time less than 24 hours before, was rewarded by the most enthusiastic applause of the day.

The remainder of the Launch Event was dedicated to a series of three themes of global concern. These sessions were led by renowned practitioners, from several walks of life, whose presentations provided the basis for interactive discussion with members of the audience.

Theme 1: Population growth and climate change: challenges for planet Earth

This theme was introduced by Aubrey Manning. The opening session included a presentation by Nikita White (Ireland), the first of three winners of a student competition involving original essays or poemsextracts from which prefaced the discussion of each theme. Views were then presented by Renate Christ, Secretary of the Intergovernmental Panel on Climate Change (IPCC), who gave a wide-ranging review of information indicative of anthropogenic influences leading to global warming. This was a stimulating if slightly harrowing overview, followed by an equally arresting but differently angled talk by Ghislain de Marsily of the French Academy of Sciences. The theme was then taken up by Ruud Lubbers, former Prime Minister of The Netherlands, followed by the views of Arti Mehra, mayor of the City of Delhi, India. Like Professor Lubbers who illustrated the theme from his personal experience of the remarkable growth of the city of Rotterdam, Ms. Mehta spoke from the point of view of one of the largest and fastest-growing cities in the world.

The day ended with a panel discussion, with audience questions directed at the four speakers, after which participants attended by invitation a glittering reception at the Hôtel de Ville, Paris, hosted by the Mairie de Paris.

The second day was opened by Mohammed Sheya, Minister Plenipotentiary of the United Republic of Tanzania. Professor Sheya, who more than anyone else ensured the successful passage of the 2008 Planet Earth resolution through the UN General assembly, emphasised the diverse ways in which scientific study of the Earth System bears upon human well-being. He noted that the physical laws that govern natural phenomena are being used with increasing effect to predict occurrences of natural disasters. Increasing partnerships between Earth scientists and social and environmental scientists have a critical role to play in enlightening politicians, policy- and decision-makers and the general public concerning global phenomena that impact upon the Earth system and their mitigation. Such collaboration also brings to light new possibilities of exploiting Earth's resources for the benefit of human-kind without causing harm to the Earth's ecological life support system.

\section{Theme 2: Earth resources-threat or treat?}

This theme was introduced by Marina Mielczarek, Grand Reporter of Radio France Internationale. First the floor was given to Hannah Lyn Creencia, a student from the Philippines who read an essay on the topic. An industrial standpoint on the theme was presented by Thierry Desmarest, Chair of the Board of Directors of Total (the world's fourth-biggest oil company), who predicted an increase of $1.2 \%$ per annum in energy demand over the next 25 years. Global demands and production of Earth materials were presented by Mark Myers, Director of one of the world's largest geoscientific research organisations, the US Geological Survey. Vice Minister Wang Shouxiang, of the Ministry of Land and Resources in China, described the rapidly growing need for Earth materials in his country. The following panel discussion was chaired by Marina Mielczarek, who also summed up the main strands of the session.

Theme 3: Geohazards: minimizing risk, maximizing awareness

After an introduction to geohazards by Marina Mielczarek and a poem presented by the third of the student competition winners, the South African Laura Byrne, views on this increasingly publicly prominent theme came from the world of insurance. Using an impressive collection of graphics, Peter Hoeppe, Head of the Geo Risks Research Department of the Munich Reinsurance Company, Germany, showed how hazard and risk are quantified as a means of assessing reinsurance cases in a competitive business environment.

The final scientific view on the theme was presented by Sospeter Muhongo, Director of the Regional Office for Africa of the International Council for Sciences (ICSU), South Africa, and the newly appointed Chair of the Science Programme of the IYPE. He considered a broad sweep of information and case studies bearing upon the theme, bringing together several perpectives. The succeeding panel discussion was a busy one and, before closing the third Session, a summary was presented by Marina Mielczarek.

The closing remarks of the UNESCO Director-General re-emphasized the pivotal importance of the Earth sciences in tackling the many challenges faced in the modern world, the value of Earth science data in anticipating and solving real life problems and the potential that Earth sciences possess for ensuring improved and sustainable management and planning by decision makers. Knowledge of the Earth system is humankind's insurance policy for the future. This theme ran through the recorded audio message of Sir Arthur C. Clarke which, in positive style, sent the delegates away with much to think about and an IYPE organisation optimistic about the taking up of its aims by industry, scientists and politicians. This Event served as a plaform from which other regional and national events will be launched around the world until the end of the IYPE triennium and beyond.

For more information about the IYPE Global Launch Event, please check: www.yearofplanetearth.org/GLE

\section{Dr. Eduardo de Mulder}

IYPE Executive Director Secretariat iype.secretariat@ngu.no

\section{Dr. Edward Derbyshie}

Former Chair IYPE Science Programme Committee

\section{Dr. Ted Nield}

Chair IYPE Outreach Committee

ted.nield@geolsoc.org.uk 


\title{
Declaration presented at the Global Launch Event of the International Year of Planet Earth (IYPE)
}

\author{
UNESCO, Paris, 12-13 February 2008
}

\section{Preamble}

Recalling that the General Assembly of the United Nations has declared 2008 as the International Year of Planet Earth;

Considering life depends on a self-sustaining Earth system that is unique, diverse and ever-changing;

Emphasizing that all decisions on global sustainability should be informed by the wealth of existing and potential Earth sciences' knowledge;

Noting that the wealth of Earth-sciences' related information available on issues like climate, water and other natural resources, energy, health, soils, the ocean, deep earth, natural hazards or life itself remain largely unknown to the public and often untapped by policy and decision makers;

Convinced that the IYPE and the Earth sciences can play a significant role in promoting the sustainable use of Earth resources and can provide valuable contributions to society through the UNESCO-led United Nations Decade of Education for Sustainable Development and the promotion of UN Millennium Development Goals, and

Persuaded that creating respect for Planet Earth, raising public awareness of the vulnerability and potential of the Earth's components and mitigating natural hazards will provide the basis for a more peaceful, prosperous and fulfilled community of nations;

\section{Therefore, we}

1. Urge decision makers of all nations to make freely available and utilize the wealth of knowledge about our Planet Earth and to encourage the development of new knowledge and technologies for the benefit of developing and developed nations alike;

2. Encourage Earth science communities, as well as public organizations and private industry, to support this initiative for the development of new knowledge and to develop strategies that will reduce the impact of natural hazards and guide sustainable development to meet the current needs of our expanding global society and of generations to come;

By

a.Improving access to Earth science knowledge through revised national educational systems and enhanced research capacity in Earth and Space Science institutions and universities;

b. Producing global, digital and publicly available information on System Earth such as "OneGeology" and "UN Spatial Data Infrastructure" (UNSDI) projects;

c. Promoting awareness of the structure, evolution, beauty and diversity of the Earth system and its human cultures inscribed in landscapes, through the establishment of "Geoparks", biosphere reserves and World Heritage Sites as a public tool for conservation and development;

d. Investing in Earth monitoring mechanisms (both remote and in-situ) for the purpose of predicting largescale changes in the Earth's spheres using and enhancing existing global Earth observation systems;

e.Establishing an International Research Centre on Earth sciences for sustainable development, and

f. Producing books, DVDs and other media tools that will make Earth scientific knowledge more accessible to the public and provide a lasting legacy for the IYPE. 